University of Rhode Island

DigitalCommons@URI

Open Access Dissertations

1978

\title{
The Relationship Between "Rapid Induction" and Placebo Analgesia, Hypnotic Susceptibility, and Chronic Pain Intensity
}

Lorraine Luke Snow

University of Rhode Island

Follow this and additional works at: https://digitalcommons.uri.edu/oa_diss

\section{Recommended Citation}

Snow, Lorraine Luke, "The Relationship Between "Rapid Induction" and Placebo Analgesia, Hypnotic Susceptibility, and Chronic Pain Intensity" (1978). Open Access Dissertations. Paper 960.

https://digitalcommons.uri.edu/oa_diss/960

This Dissertation is brought to you for free and open access by DigitalCommons@URI. It has been accepted for inclusion in Open Access Dissertations by an authorized administrator of DigitalCommons@URI. For more information, please contact digitalcommons-group@uri.edu. 


\section{THE RELATIONSHIP BETWEEN "RAPID INDUCTION" AND PLACEBO ANALGESIA, HYPNOTIC SUSCEPTIBILITY, AND CHRONIC PAIN INTENSITY}

BY

LORRAINE LUKE SNOW

A DISSERTATION SUBMITTED IN PARTIAL FULFILLMENT OF THE REQUIREMENTS FOR THE DEGREE OF DOCTOR OF PHILOSOPHY

IN

CLINICAL PSYCHOIOGY 
"RAPID INDUCTION" AND PLACEBO ANALGESIA 


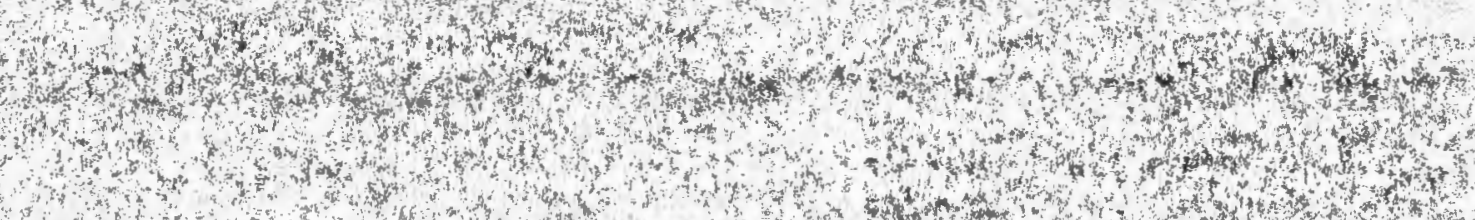 \\ ABSTRACT}

The effects of Rapia (hypnotial induotzon Analges la (RIA) and an oral placebo on clinical and experimental pain were compared in 30 volunteer male paraplegic veterans with chronic pain synarome scores for hypnotic susceptibilit and chron pa poxperince were alo correlated with the effects of Rid on clinical and experimental pain. Self-ratings of S's clinlcal pain on a 0-100 scale were obtained before and after RIA and placebo treatments: and Threshold and tolerance for lscheml musle pain texperimental pain) was measured during baseline control RTA and placebo sessions. The general linear hypothesis was used to analyse the data. The results Indicate that hIA is not significantly more effective than an ora placebo in (a) reducing clinical pain and (b) increasing exper mental pain tolerance (when the effect of hypnotic suscep tibility is controlled). The effect of treatment (RIA on placebo) is not related to either chronic pain experience or pre-treatment 0-100 pain ratings (when the effect of hypnotic susceptibility is controlled). The effect of RIA is not significantly related to hypnotic susceptibility for clinical or experimental pain (when the effect of chronic pain experience is controlled). In conolusion, the effectiveness of a single RIA session for the contral 


\section{ACKNOWLEDGEMENTS}

I wish to express my sincere appreciation to the Psychology Staff of Long Beach Veterans Administration Hospital, especially Reed Boswell and Donald Carver who assisted in the data collection and statistical analysis, respectively. David Davis also assisted in the data collection, and Rajendra Tiwari was responsible for the physical screening of candidates.

The consistent caring and encouragement of Alan Willoughby, my advisor, have been instrumental in the completion of this dissertation.

I also wish to thank the spinal cord injured pain patients who participated in this study. 
TABLE OF CONTENTS

Page

LIST OF TABLES . . . . . . . . . . . . . . . iv

LIST OF FIGURES . . . . . . . . . . . . . . V V

INTRODUCTION . . . . . . . . . . . . . . . 1

METHOD . . . . . . . . . . . . . . . . . 9

RESULTS . . . . . . . . . . . . . . . 27

DISCUSSION . . . . . . . . . . . . . . . . . 4 4

CONCLUSION . . . . . . . . . . . . . . . 49

REFERENCES .................. . . . 51

APPENDIX . . . . . . . . . . . . . 55 


\section{LIST OF TABLES}

Table

1. Comparison of Full and Restricted Models for Clinical Pain for Hypotheses 4 and 2 . 35

2. Comparison of Full and Restricted Models for Experimental Pain for Hypotheses 4 and 2

3. Comparison of Full and Restricted Models for Clinical Pain for Hypotheses 3 and 1 . 36

4. Comparison of FuIl and Restricted Models for Experimental Pain for Hypotheses 3

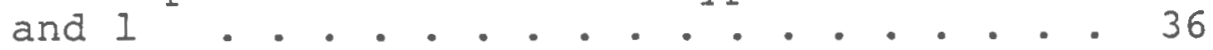

5. Means and Standard Deviations of Variables . 37

6. Intercorrelations of Variables . . . . . . 38 
LIST OF FIGURES

Figure

Page

1. Procedural Flow Chart . . . . . . . 23 
The purpose of this study was to investigate the relationship between response to Rapid Induction Analgesia (RIA) and certain characteristics of the chronic pain patient. Specifically, the effects of RIA on clinical and experimental pain were compared to the effects of an oral placebo on clinical and experimental pain in 30 volunteer paraplegic patients with chronic pain. Hypnotic susceptibility and chronic pain experience were also correlated with the effects of RIA on clinical and experimental pain.

Definition of Chronic Pain

Chronic pain is defined as pain of six months or more duration. It may either accompany an ongoing disease process, such as cancer, or a stabilized medical condition, such as spinal cord injury. Chronic pain which accompanies a stabilized medical condition is referred to as benign.

The Need for Research on Chronic Pain

Pain is the most common symptom that compels patients to seek medical attention (Bonica, 1974). As a disabling disease, chronic pain constitutes a serious world health and economic problem. Unlike acute pain, chronic benign pain serves neither as a warning signal nor as a diagnostic aid. Medical approaches which suc- 
cessfully alleviate acute pain (e.g., chemical and/or surgical intervention) frequently fail to manage chronic pain and may produce narcotic addiction and/or mutilation. Chronic pain syndromes often impose severe emotional, physical, and economic stress on patients, families, and society for long periods of time.

Chronic pain patients bring a complex mixture of psychological factors, motivational factors, and past experience to the treatment situation. Unlike their acute counterparts (for whom pain may be a warning signal), they cannot ascribe meaning to the pain, with the result that they are subject to a variety of psychological consequences incluaing irritability, anxiety, and depression (Sternbach, 1974). Reported studies of chronic pain patients support the premise that pain experienced over a prolonged period of time is accompanied by negative personality changes (Sternbach, Murphy, Akeson, \& Wolf, 1973; Wolff \& Wolf, 1958; Woodforde \& Merskey, 1972). Chronic pain patients may use their pain in the service of interpersonal needs or they may be rewarded for hurting, as in the receipt of insurance compensation payments. Often, they have experienced many unsuccessful attempts to alleviate the pain. The investigation of mechanisms and management of chronic pain, as a valid research area distinct from that of acute pain, is relatively new (Bonica, 1974). Interest in the basic neurological mechanisms, the 
development of animal models, and the clinical application of management techniques for chronic pain syndromes has recently grown, culminating in the first multidisciplinary International Symposium on Pain which convened in 1973. The Role of Psychology in the Field of Chronic Pain

Approaches which would not be viable in the management of acute pain may constitute the treatment of choice for chronic pain. It is an area in which psychologists are making a significant contribution. In both the application and evaluation of treatment strategies psychologists are uniquely suited. Not only does their training enable them to confront chronic pain syndromes in the context of dealing with the total person and problems of living, but it enables them to scientifically evaluate the efficacy of various treatment methods. Psychologists and other professionals currently use behavior modification, hypnosis, autogenic training, and transcutaneous stimulation, in combination or separately, in chronic pain treatment clinics throughout the United States. Much of the psychological research regarding chronic pain syndromes has been limited to psychogenic pain, while the treatment and investigation of pain with a clear organic etiology has been relegated to medicine. Nevertheless, the application of hypnotic analgesia to somatogenic pain is generally more appropriate than its application to psychogenic pain, where the pain may serve an an important coping mechanism (Orne, 1974). 
Rapid Induction Analgesia (RIA)

The clinical use of hypnosis to control pain has traditionally been limited, in part, because of the widely-held view (T. Barber, 1963) that hypnosis is ineffective as an analgesic in most people. In fact, the amount by which pain is reduced through suggestions of analgesia consistently correlates with hypnotic susceptibility (Evans \& Paul, 1970; Gottfredson, 1973; Hilgard, 1967; MCGlashan, Evans \& Orne, 1969; Shor, 1959). Therefore, the probability of successful pain reduction through suggestions of analgesia is high (but not certain) only for those who are highly susceptible to hypnosis (Hilgard \& Hilgard, 1975).

Nevertheless, Joseph Barber (1976, 1977) concludes that hypnotic analgesia might be much more widely applicable than previously believed. He derives this conclusion from his work with a technique to rapidly induce a state of hypnotic analgesia which he refers to as Rapid Induction Analgesia (RIA). This technique is based on Milton Erickson's indirect approach (Erickson, 1964; Erickson \& Erickson, 1941; Erickson, Hershman \& Sector; Erickson, Rossi \& Rossi, 1976). It differs most strikingly from the more direct hypnotic techniques used in previous studies of hypnotic analgesia in that the analgesic suggestions are always indirectly framed in a posthypnotic context.

Using the RIA technique, Mayer, Price, J. Barber, 
\& Rafii (1976) effectively controlled experimental dental pain (electrical tooth pulp stimulation) up to an arbitrarily defined limit of 340 volts in 27 out of 27 volunteer Ss. Using RIA, J. Barber (1977) effectively controlled clinical dental pain (for fillings, root canal treatments, crown preparations, and extractions) in 99 out of 100 patients. In both of these studies the "effective control" of pain was defined in terms of increasing pain threshold or preventing the experience of pain; 126 out of 127 Ss did not indicate any experience of dental pain following RIA. These results paired with J. Barber's (1976) finding that the effectiveness of RIA is unrelated to hypnotic susceptibility suggest that hypnotic analgesia produced by "rapid induction" is universally effective in the control of dental pain regardless of hypnotic susceptibility.

Since RIA had only been applied to dental pain, its effectiveness in controlling other types of clinical and experimental pain needed to be investigated. Its applicability to chronic pain syndromes was of particular interest because of the frequent failure of chemical and/or surgical approaches to manage pain in these cases.

To investigate the effectiveness of RIA in controlling chronic pain syndromes the present study evaluated its effect on clinical pain, as measured by the subjectively rated "Pain Estimate" (Sternbach, 1974), and on experimental pain, as measured by time to pain threshold 
and time to maximum pain tolerance during a modified Submaximum Effort Tourniquet Test, in 30 volunteer paraplegic patients with chronic pain. Although the effects of RIA on clinical and experimental pain were expected to be consistent, it was desirable to include both, because subjective pain ratings may readily be affected by response bias and compliance (Evans, 1974).

Unlike the previous studies which investigated the effect of RIA in preventing the experience of pain, the present study evaluated the effect of this technique on suprathreshold clinical and experimental pain. This is a better test of the applicability of RIA because it more closely resembles the clinical situation of pain management and because threshold measures "have been notoriously unreliable, and are prone to the response bias inherent in subjective reports, particularly when it is clear to the $\underline{\mathrm{S}}$ what is . . expected and desired . . ." (Evans, 1974). In addition, it was necessary to obtain measures of hypnotic susceptibility, placebo response, and chronic pain experience for each $\underline{s}$ in order to assess the relationship between these variables and response to RIA.

To insure that results obtained using RIA were not the product of a particularly fortuitous sample (e.g., one in which all ss are highly susceptible), it was imperative to measure hypnotic susceptibility. Hilgard \& Hilgard (19.75) repeatedly criticize authors who draw con- 
clusions about hypnosis on the basis of studies which failed to measure the hypnotic susceptibility of the $\underline{s}$ sample. Hypnotic susceptibility was measured with the revised Stanford Profile Scales of Hypnotic Susceptibility: Form II (SPSHS: II) (Weitzenhoffer \& Hilgard, 1967).

The effects of an oral placebo on clinical and experimental pain were measured using changes in the clinical "Pain Estimate" (Sternbach, 1974); time to pain threshold and time to maximum pain tolerance on the Tourniquet Test, respectively. Previous research has demonstrated that placebo analgesia is not related to secondary suggestibility, or situational anxiety (Evans, 1967, 1969, 1974; Hilgard \& Hilgard, 1975).

Evaluating chronic pain experience involves not only gathering information about the sensory and intensity qualities of the experience, but also assessing the individual's emotional reaction to the pain. Chronic pain experience was measured by the McGill Pain Questionnaire. Scores on this variable typically distinguish chronic pain patients from the normal population. Clinical experience led the author to believe that chronic pain experience would be related to the effects of RIA. Hypotheses to Be Tested

There were four hypotheses to be tested. The first two hypotheses were logical implications derived from Joseph Barber's results in applying RIA to dental pain. 
The third and fourth were based on the author's clinical experience.

Hypothesis 1. RIA is significantly more effective than an oral placebo in (a) reducing clinical pain, and (b) increasing experimental pain tolerance when the effects of hypnotic susceptibility and chronic pain experience are controlled.

Hypothesis 2. The effect of RIA on (a) clinical pain and (b) experimental pain is not significantly related to hypnotic susceptibility when the effect of chronic pain experience is controlled.

Hypothesis 3. Differences between the effect of RIA and the effect of an oral placebo on clinical pain are not constant for different levels of pre-treatment clinical Pain Estimates when the effects of hypnotic susceptibility and chronic pain experience are controlled. Hypothesis 4. The effect of RIA on (a) clinical pain and (b) experimental pain is significantly related to chronic pain experience when the effect of hypnotic susceptibility is controlled. 
METHOD

Selection of subjects

A review of the research literature on pain reveals that conclusions are frequently based on studies done with samples of individuals who have acute pain or who were subjected to short-term experimental pain in the absence of clinical pain. Attempts to generalize the results of these studies to chronic pain syndromes are highly questionable, because acute and experimental pain situations are not analogous to chronic pain in their emotional and physiological impact. It is therefore essential that investigations involving the management of chronic benign pain be accomplished by sampling from a chronic benign pain population. (Chronic benign pain is here defined as pain of six months or more duration, where there is no active disease process.) The present study selected spinal cord injured (SCI) patients because their pain is organic in origin, usually resulting from scarring of neural tissue.

The Ss consisted of 30 male volunteer SCI paraplegic veterans with chronic pain syndrome. They ranged in age from 23 to 79 and in duration of pain from six months to 34 years. The Ss were recruited through the SCI Service at Long Beach Veterans Administration Hospital (LBVAH), 
Long Beach, California. They included both inpatients and outpatients who complained of SCI pain. Initial contact was through self-referral or physician referral to the SCI Pain Clinic, or in response to an ad in the Paralyzed Veterans' Bulletin for paraplegics with pain of six months or more duration. It was made clear that whether or not the individual participated in/ or completed the study, he would be offered a pain management program.

Ss were medically evaluated for the study to eliminate candidates with a recent history of cardiovascular problems. In addition to the $30 \mathrm{Ss}$ who completed the study, two candidates were eliminated because of cardiovascular problems and one $\underline{S}$ did not complete the study. History and physical examination. Each $\underline{\mathrm{S}}$ was interviewed by a physician to obtain a medical history focusing on his cardiovascular system. In addition, he was given a physical examination including a Rumpel-Leede Test of capillary fragility. Any $\underline{S}$ whose physical condition might conceivably be compromised by the Tourniquet Test, or who was currently under treatment for psychosis or severely brain damaged was excluded.

Measurement

The variables pertaining to the hypotheses to be tested were measured using the following instruments: the "Pain Estimate" (Sternbach, 1974); the modified 
Submaximum Effort Tourniquet Test; the revised Stanford Profile Scales of Hypnotic Susceptibility: Form II (SPSHS: II) (Weitzenhoffer \& Hilgard, 1967); and the McGill Pain Questionnaire (Melzack, 1975). The "Pain Estimate" (Sternbach, 1974). Quantification of pain is important in evaluating the extent of patients' suffering and the effect of various treatment modalities on pain. Most often the patient describes pain in terms of its character and expresses its intensity in non-numerical values, which makes assessment difficult, if not impossible.

In the inpatient Pain Unit of San Diego Veterans Administration Hospital, patients are routinely asked to rate the intensity of their pain on a scale of 0-100 in which " 0 is no pain at all, and 100 is pain so severe you'd commit suicide if you had to endure it more than a minute or two" (Sternbach, Murphy, Timmermans, Greenhoot, \& Akeson, 1974). The s's rating on this 0-100 scale constitutes the "Pain Estimate."

Aside from good face validity, Sternbach reports dramatic reductions in the Pain Estimate following treatment interventions. Boswell (personal communication, 1978) has computed one hour test-retest reliability of $\underline{r}=.97(\mathrm{~N}=66)$ for SCI chronic pain patients.

This measure was selected for use in the present study because it is easy for patients to understand and 
work with, it is quickly made, and it is sensitive to change.

The pre- and post-treatment clinical Pain Estimates obtained for Sessions B (RIA) and C (placebo) constitute the data from which the effect of RIA and of placebo medication on clinical pain was calculated.

The modified Submaximum Effort Tourniquet Test. To overcome the difficulties inherent in subjective pain scales, attempts have been made by several researchers to develop objective pain scales. The production of ischemic muscle pain (IMP) as an objective measure of pain was originally developed by Lewis (1929) at the University College Hospital in London. He felt that an objective pain test was critical for accurate diagnosis and understanding of the mechanisms of pain. In more recent years several investigators have continued to develop and use this measurement method (Caldwell \& Smith, 1966; Dorpat \& Holmes, 1955). The Submaximum Effort Tourniquet Test represents the most recent modification of this technique (Smith, Egbert, Markowitz, Mosteller, \& Beecher, 1966; Smith, Lowenstein, Hubbard, \& Beecher, 1968; Smith \& Beecher, 1969).

Ischemic muscle pain (IMP) is that pain which is experienced when blood flow to a limb is occluded and develops more rapidly when the limb is exercised. In early research IMP was produced by occluding blood flow 
and sustaining a contraction strength of $11 \mathrm{~cm}$. mercury $(\mathrm{Hg})$, by squeezing a rubber bulb, attached by rubber tubing to a mercury manometer. On the average, pain first developed at 32 seconds and became intolerable at 130 seconds. The maximum length of contraction was limited to 150 seconds at which point the contraction amplitude involuntarily fell. The pain produced is deep, dull, and diffuse, increasing steadily in intensity as the test proceeds. When circulation to the limb is re-established, the pain vanishes completely in three to five seconds.

The apparatus for the Tourniquet Test includes:
(a) a Vantage sphygmomanometer,
(b) a Baunanometer with

a $300 \mathrm{~mm}$. vertical $\mathrm{Hg}$ column, (c) a Rustrak four channel event recorder, (d) three Gerbrand cumulative recorders, and (e) a Semiconductor 24 volt D.C. power supply. The Baumanometer has four insulated copper wires inserted into the $\mathrm{Hg}$ column with barred tips of $2 \mathrm{~mm}$. The common wire extends the full length of the Hg column. Barred tips of the other three wires are positioned at 90, 100, and $110 \mathrm{~mm}$. in the $\mathrm{Hg}$ column. Three Gerbrand cumulative timers were used to record accumulated time that the $\mathrm{Hg}$ column exceeded $90 \mathrm{~mm}$. Hg (Channel 1), $100 \mathrm{~mm}$. Hg (Channel 2), and $110 \mathrm{~mm}$. Hg (Channel 3). The 24 volt D.C. power supply provided the current to activate the four channels of the Rustrak recorder. The Rustrak event recorder, operating at 15 seconds/inch recorded the level of $\mathrm{Hg}$ 
for the Baumanometer column at $90 \mathrm{~mm}$. (Channel 1), 100 mm. (Channel 2), and $110 \mathrm{~mm}$. (Channel 3). Channel 4 was activated by a response key operated by $\underline{S}^{\prime} s$ nondominant hand. As $\underline{S}$ pumped the Baumanometer bulb, the Hg rose in the column and a circuit was completed through the barred wire tips at 90, 100, and $110 \mathrm{~mm}$. $\mathrm{Hg}$.

The $\underline{S}$ was seated in his wheelchair with dominant forearm resting on the apparatus table in a position that allowed him to grasp the Baumanometer bulb. His nondominant arm rested extended on a foam rubber cushion with index finger in contact with the response key. $\underline{s}$ was given instruction in the Tourniquet Test procedure.

Circulation to the s's exercising forearm was reduced by first extending the arm toward the ceiling and then using an elastic Ace bandage to drain the arm of venous blood. Immediately before removing the elastic Ace bandage, the Vantage sphygmomanometer cuff was placed around the $\underline{S}^{\prime} s$ upper arm and inflated to a pressure of $250 \mathrm{~mm}$. $\mathrm{Hg}$. The $\mathrm{S}$ then lowered his arm to the apparatus table and, after a pause of 60 seconds, began pumping the bulb to raise the $\mathrm{Hg}$ column to $100 \mathrm{~mm}$. and maintain it at that level for one minute. (This time period was determined and the bleed on the Baumanometer bulb adjusted in an attempt to insure that ss reached maximum pain tolerance no more than 180 seconds after they finished pumping (as required by the Research and 
Development Committee of LBVAH). S was instructed to press the response key: (a) when he first experienced IMP (threshold), and (b) when he experienced the IMP as unbearable (maximum tolerance). II monitored each $\underline{\mathrm{S}}$ during the Tourniquet Test to insure that $\underline{\mathrm{s}}$ maintained the $\mathrm{Hg}$ column between 90 and $110 \mathrm{~mm}$. for the one-minute interval. Channels 1-3 of the Rustrak recorder provided time measures for the level of $\mathrm{Hg}$ at 90,100 , and 110 mm. Channel 4 recorded time to threshold, and maximum IMP tolerance. The cumulative counters provided an accurate measure of the amount of $\mathrm{Hg}$ displaced during the time period for the Tourniquet Test. The apparatus is designed to provide a constant rate of work over time. During the Tourniquet Test there exists a rare possibility of arterial thrombosis due to extra-arterial compression. Extra-vasation of blood from the capillaries may occur due to obstruction of venous blood flow from the limb. These possibilities were minimized, if not completely eliminated, by careful selection of $\underline{s}$. Those with a history of arterial diseases such as hypertension, arteriosclerosis, angina pectoris, myocardial infarction, and cerebrovascular episodes were excluded from the study. Candidates who were known to have a bleeding diathesis or who were on anticoagulants were also excluded.

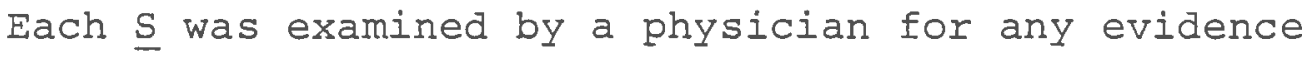


of arterial or venous disease with particular emphasis on the extremity to be used for the Tourniquet Test. A capillary fragility test (Rumpel-Leede test*) was done and only those whose results were normal were included in the study.

Ischemic muscle pain (IMP) offers an objective measure of pain threshold and tolerance. It is essential to use an objective measure of pain when comparing the effectiveness of different treatment modalities in pain management for two reasons. First, it permits inter-subject comparisons for a quantified stimulus (as might be used in cross-cultural studies). Second, it permits intra-subject comparisons which are critical in evaluating treatment methods.

of the available objective pain measures, the ischemic measure is superior for a number of reasons: (a) IMP is experienced as diffuse, deep, and dull, and is more comparable to common clinical pain than that produced by electric shock or focused intense heat; it is brief and its duration is controlled by the $\underline{\text {; }}$ (c) muscle contraction will involuntarily release well

${ }^{*}$ A circle $2.5 \mathrm{~cm}$. in diameter is marked on the skin over the anteromedial aspect of the forearm with the upper edge of the circle $4 \mathrm{~cm}$. below the flexor crease of the elbow. The cuff of a sphygmomanometer is then applied around the arm above the circle and half-inflated to a pressure midway between systolic and diastolic blood pressure for five minutes. A count of petichiae within the circle is made. Less than ten is normal. 
before the ischemia can become physically harmful;

its validity is supported by the fact that it responds to analgesic medication (Smith, Egbert, Markowitz, Mosteller, \& Beecher, 1966; Smith, Lowenstein, Hubbard, \& Beecher, 1968; Smith \& Beecher, 1969); and (e) testretest reliability for maximum pain tolerance on the Submaximum Effort Tourniquet Test has been reported as $\underline{r}=.89(\mathrm{~N}=38)$ for one week (Sternbach, Murphy, Timmermans, Greenhoot, \& Akeson, 1974).

The Tourniquet Test provided two time measures, time to pain threshold and time to maximum pain tolerance as measured from the point when the Hg column first reached the 90-110 criterion range from which the effect of RIA and of placebo medication on experimental pain were calculated.

The Revised Stanford Profile Scales of Hypnotic Susceptibility: Form II (SPSHS:II) (Weitzenhoffer \& Hilgard, 1967). The SpSHS is designed to yield not only a measure of general hypnotic susceptibility, but measures of differential susceptibility to a variety of suggestions within the induced hypnotic state. As in most measures of hypnotic responsiveness, a brief standard induction of hypnosis is given followed by increasingly difficult suggestions (tests) to which hypnotized persons are known to respond.

A total score of 27 is possible on both Forms I and 
II, and a profile reflecting special areas of susceptibility can be constructed using the six subscales provided. These include: (a) Agnosia and Cognitive Distortion (AG); (b) Hallucinations-Positive (HP); (c) Hallucinations-Negative (HN); (d) Dreams and Regressions (DR); (e) Amnesia and Post-hypnotic Compulsions (AM); and (f) Loss of Motor Control (MC). Although these subscales group tests on the basis of intended functions (face validity), they take into account the results of factor analysis (Lauer, 1965) of the original Stanford Hypnotic Susceptibility Scale (SHSS), Forms A and B (Weitzenhoffer \& Hilgard, 1959).

The standardization sample on which reliability estimates are based consists of 155 Stanford University undergraduates (70 males and 85 females) who had previously taken the SHSS, Forms $A$ and $C$. The sample is not random because of self-selection factors and the elimination of Ss who scored $0-3$ on Form $A$ (because of the frustrations inherent in spending two hours in testing when essentially nothing that is suggested happens).

The Manual reports that there is little practice effect, and Forms I and II can be considered equivalent. (There is no significant difference in their means.) By considering each form as half of a longer 54-point test, the split-half reliability coefficient (reflecting 
internal consistency) stepped up by the spearman-Brown Formula is .88. Test-retest reliability based on the product-moment correlation between the total scores of Forms I and II is .78. This estimate is actually low because it excludes the scores of very poor hypnotic Ss whose performance is very consistent. Subscale reliabilities stepped up by the Spearman-Brown Formula range from .66 to .86. Subscale intercorrelations range from .38 to .68 indicating the presence of a common factor running through the subscales, although they are independent enough to be valuable.

In the present study, hypnotic susceptibility was measured by the total score of the SPSHS:II.

The McGill Pain Questionnaire (Melzack, 1975). The McGill Pain Questionnaire was designed to provide quantitative measures of clinical pain that can be treated statistically. It is unusual in that it focuses not only on the intensity dimension of pain perception, but on the sensory and affective qualities of the experience. The questionnaire was originally constructed by

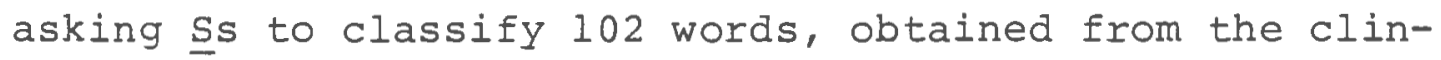
ical literature relating to pain into smaller groups that describe different aspects of pain experience. On the basis of the data, the words were categorized into three major classes and 16 subclasses. The classes are: words that describe the sensory qualities of the experience 
in terms of temporal, spatial, pressure, thermal, and other properties; (b) words that describe affective qualities in terms of tension, fear, and autonomic properties that are part of the pain experience; and (c) evaluative words that describe the subjective intensity of the total pain experience.

To determine the pain intensities implied by the words within each subclass, groups of doctors, patients, and students were asked to assign an intensity value to each word, using a numerical scale ranging from 1 to 5 in which each number is associated with the following words: 1, mild; 2, discomforting; 3, distressing; 4, horrible; 5, excruciating. Although the precise intensity scale values differed for the three groups, all three agreed on the positions of the words relative to each other. This agreement on the intensity relationships among pain descriptors is all the more impressive given the different cultural, socio-economic, and educational backgrounds of the $\underline{S}$.

The questionnaire is comprised of a top sheet to record medical information (such as diagnosis and drug intake), line drawings of the body to indicate the spatial distribution of pain, and a list of pain descriptors divided into subclasses and rank ordered. The $\underline{S}$ is instructed to select those words that describe his present pain, omitting any categories that are unsuitable and selecting 
a single word in each appropriate category. (Category and subclass are used synonymously here.) The questionnaire is completed with the aid of an administrator who reads the instructions aloud and answers any questions that $\underline{S}$ may have. Fifteen to twenty minutes are typically required for the initial administration.

The Pain Rating Index based on the patients' mean scale values (PRI(S)) is derived from the work of Melzack \& Torgerson (1971). The assigned values of the words chosen by $\underline{S}$ are added up to obtain a score for each category and a total score for all categories. Because the PRI(S) relies primarily on the specification of pain properties such as burning, wrenching, and shooting, it is less subject to the effects of immediate psychological factors than most pain measures (Melzack, 1975).

The PRI(S) of the McGill Pain Questionnaire constituted the measure of chronic pain experience.

\section{Procedure}

The present investigation was presented to the $\underline{S}$ as a study to compare the effectiveness of hypnosis and a strong analgesic medication for relief of pain. Medical, rather than psychological overtones of the research were stressed.

The study consisted of three sessions, each separated by at least 48 hours: (a) Baseline control, Hypnotic analgesia, and (c) Placebo analgesia. Ss were 
assigned to treatment sequence $A, B, C$ or $A, C, B$. Three Investigators ( $I_{1}, I_{2}$, and $I_{3}$ ) collected the data. To control for experimenter bias, each I had no knowledge of

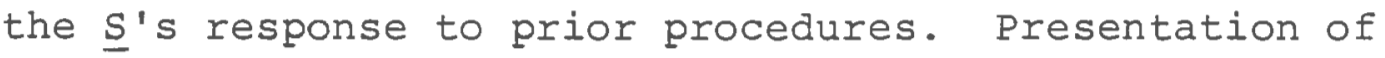
the two treatment sequences was varied so that II did not know which treatment had preceeded her administration of the Tourniquet Test. Figure $I$ is a flow chart depicting the three sessions, including medical procedures, Tourniquet Tests, and self-ratings by the $\underline{S}$.

Initial evaluation. At the time of scheduling for initial evaluation at the SCI Pain Clinic, $\underline{S}$ was instructed not to take any medication (prescribed or other) within four hours of the evaluation appointment or the three datagathering sessions.

During the evaluation, a physician completed the S's cardiovascular history and physical examination. $\underline{S}$ then read and signed the consent form. S was asked to rate his present clinical pain on a Pain Estimate scale from 0-100, where 0 represents the absence of pain and 100 represents a degree of pain which would make living intolerable (Sternbach, 1974). The McGill Pain Questionnaire and the Stanford Profile scales of Hypnotic Susceptibility: Form II (SPSHS:II) were then administered by $I_{2}$. Next $I_{1}$ read aloud instructions explaining the Tourniquet Test and the sensations to be expected. She simulated the procedure with $\underline{S}$ (without actually using the 


\section{Initial Evaluation}

Physician completes cardiovascular problem interview

Physician administers Rumpel-Leede Test

$S$ reads and signs consent form

$\bar{S}$ rates current clinical pain (0-100)

$\bar{I}_{2}$ administers MoGill Pain Questionnaire

I $_{2}$ administers SPSHS:II

S simulates Toumiquet Test

$\bar{I}_{1}$ administers practice Toumiquet Test

Il administers Tourniquet Test

Session A

$S \quad \begin{aligned} & \text { rates current clinical pain }(0-100) \\ & \text { simulates Tourniquet Test }\end{aligned}$
$\bar{I}_{1}$ interview re: past adverse reactions to meds
$\bar{S}_{I_{1}}$ rates current clinical pain $(0-100)$
$\bar{I}_{1}$ admisters Tourniquet Test

\section{Session B}

$S$ rates current clinical pain (0-100)

$\bar{S}$ simulates Toumiquet Test

$\bar{I}_{2}$ implements RIA

If delivers post-hypnotic cue for analgesia

$\bar{S}^{1}$ rates current clinical pain $(0-100)$

$\bar{I}_{1}$ administers Toumiquet Test

\section{Session C}

$$
\begin{aligned}
\frac{S}{S} \quad \begin{array}{l}
\text { rates current clinical pain }(0-100) \\
\text { reads description of med } \\
\text { administers med } \\
\text { Nurse-35 minute waiting period during which } \underline{S} \\
\text { simulates Tourniquet Test }
\end{array} \\
\underline{S} \text { completes side effects checklist } \\
\bar{I}_{1} \text { delivers post-hypnotic cue for analgesia } \\
\bar{S}_{1} \text { administers Toumiquet Test }
\end{aligned}
$$

FIG. 1. Procedural flow chart. S proceeds from Initial Evaluation through Sessions A, B, C or through A, C, B. 
apparatus). To further insure s's understanding of the procedure, a shortened practice trial was administered using S's nondominant arm without inflating the sphygmomanometer cuff. $\underline{S}$ was asked to signal by pressing a key with his opposite hand to simulate: (a) the point that he first experienced ischemic pain, and (b) the maximum tolerable pain, or the point at which he could no longer continue to bear the pain. S was then asked if he was willing to continue in the study. If he agreed, the Tourniquet Test was administered using his dominant forearm. *

Session A: baseline pain response. This session was designed primarily to gather baseline data for each S. S rated his present clinical pain on the Pain Estimate (0-100) scale. To refresh his memory of the Tourniquet Test procedure, he briefly simulated that procedure (without apparatus). $\underline{I}_{1}$ then interviewed $\underline{S}$ regarding past adverse reactions to any prescribed medications. $\underline{s}$ again rated his present clinical pain on the Pain Estimate (0100) scale, and the Tourniquet Test was administered. Session B: hypnotic analgesia. S rated his present clinical pain on the Pain Estimate (0-100) scale. To refresh his memory of the Tourniquet Test procedure

*These data were not included in the data analysis. 
he briefly simulated that procedure (without apparatus). $I_{2}$ implemented RIA (see Appendix), awakened $\underline{S}$, and before leaving, requested that $\underline{S}$ not tell $\underline{I}_{1}$ which treatment he had been given. $I_{1}$ entered, delivered the post-hypnotic cue for analgesia, and asked $\underline{S}$ to rate his present clinical pain on the Pain Estimate (0-100) scale. The Tourniquet Test was then administered.

Session C: placebo analgesia. S rated his present clinical pain on the Pain Estimate $(0-100)$ scale. $I_{3}$ then read aloud to $\underline{s}$ written information about the pharmacology of analgesia and the particular "medication" being used. Its virtues were extolled to the point of indicating its comparability to any other prescribed analgesic. At this point the placebo was administered by a nurse who had been told that he/she was participating in a double blind drug study. (This placebo was an inert capsule provided by LBVAH Pharmacy Service especially for this study.) S was observed for "side effects" while the "medication" took effect, and near the end of this waiting period he again simulated the Tourniquet Test procedure (without apparatus). Thirty-five minutes after administration of the placebo $\underline{s}$ was asked to fill out a medication side effects checklist and to record any other observations he wished to make about his experience. Before leaving, $I_{3}$ requested that $S$ not tell $I_{1}$ which treatment he had been given. $I_{1}$ entered and delivered 
the post-hypnotic cue for analgesia. S again rated his present clinical pain on the Pain Estimate (0-100) scale and underwent the Tourniquet Test. Before leaving, he was assured that any effects of the medication would subside within two hours.

At the end of the last session, a standard postexperimental inquiry was conducted to discuss the s's performance and perceptions of the study with him. At that time, $\underline{s}$ was given an appointment for debriefing. 


\section{RESULTS}

The data for analysis to test the hypotheses included the following variables:

(a) the pre-treatment clinical Pain Estimates for Sessions $B$ and $C$;

(b) the post-treatment clinical Pain Estimates for Sessions $B$ and $C$;

(c) time to pain threshold on the Tourniquet Test for Sessions A, B, and C;

(d) time to maximum pain tolerance on the Tourniquet Test for Sessions A, B, and C;

(e) the total score for hypnotic susceptibility from the SPSHS:II; and

(f) the PRI(S) score from the MCGill Pain Questionnaire. The time measures from the Tourniquet Test ( $c$ and $d$ ) were adjusted by square root transformation to approximate a more linear distribution for each of these two variables (Walker \& Lev, 1953).

General linear hypothesis methodology was used to evaluate the hypotheses (Bottenberg \& Ward, 1960; Kerlinger \& Pedhazur, 1973; Ward \& Jennings, 1973). This approach allowed the use of linear models which were not restricted to the linear models used in classical analysis of variance (ANOVA) and analysis of covariance (ANCOVA). (It may be 
noted at this point that classical fixed effects ANOVA and ANCOVA are subsets of general linear hypothesis methodology). General linear hypothesis methodology is useful in addressing problems concerned with complex phenomena because it allows flexibility in formulating the questions to be answered and then structures the statistical analysis in those terms.

In this type of methodology, two linear models (i.e., regression equations) are compared in terms of the reduction of the multiple correlation coefficient squared $\left(\underline{R}^{2}\right)$. The model with the larger number of predictors is referred to as the full model, and the model with the smaller number of predictors is called the restricted model. The reduction in $\underline{R}^{2}$ is $\underline{F}$ distributed with degrees of freedom df $\mathrm{df}_{1} / \mathrm{df}_{2}$ according to the following equation (Carver, et al., 1977).

$$
\begin{aligned}
& \underline{F}=\frac{\left(\underline{R}_{f}^{2}-\underline{R}_{r}^{2}\right) /(\underline{d f})}{I} \\
& \underline{R}_{f}{ }^{2}=\underline{R}^{2} \text { of the full model, } \\
& R_{r}{ }^{2}=\underline{R}^{2} \text { of the restricted model, } \\
& \underline{(d f}_{1}=\underline{n}_{f}-\underline{n}_{r} \text {, the difference between the } \\
& \text { number of linearly independent predictor } \\
& \text { vectors of the full }\left(\underline{n}_{f}\right) \text { and restricted } \\
& \left(\underline{\mathrm{n}}_{\mathrm{r}}\right) \text { models, and } \\
& \underline{\text { dff }}_{2}=\underline{N}-\underline{n}_{f} \text {, where } \underline{N} \text { is the total number of } \\
& \text { cases. }
\end{aligned}
$$


In this investigation each hypothesis was tested by comparing an appropriate full model (having the larger number of predictors) with a corresponding restricted model (having the smaller number of predictors) in terms of the reduction of $\underline{R}^{2}$.

The design of this experiment can be described in terms of criterion and predictor variables. There are two criterion variables each for Hypotheses 1, 2, and 4: a clinical pain variable and an experimental pain variable. Hypothesis 3 has only a clinical pain criterion variable. For all four hypotheses the clinical pain criterion variable includes two measures: the post-treatment clinical Pain Estimates for Sessions $B(R I A)$ and $C$ (placebo). The experimental pain criterion variable also includes two measures: time to maximum pain tolerance on the Tourniquet Test for Sessions B (RIA) and C (placebo). A separate linear models analysis for clinical pain and for experimental pain was necessary to evaluate each of Hypotheses 1, 2, and 4. A single linear models analysis for clinical pain was necessary to evaluate Hypothesis 3 . The predictor variables include treatment, covariate, and subject variables. The treatment variable can be broken down into two levels, RIA and placebo. For clinical pain the covariates are pre-treatment clinical Pain Estimates for Sessions B (RIA) and C (placebo), the total score for hypnotic susceptibility from the SPSHS:II, and the PRI(S) score from the McGill Pain Questionnaire. 
For experimental pain the covariates are time to threshold for Sessions A (baseline), B (RIA), and C (placebo); time to maximum pain tolerance for session A (baseline); the total score for hypnotic susceptibility from the SPSHS:II; and the PRI(S) score from the McGill Pain Questionnaire. Rather than using pre-post difference scores, the effect of treatments was analyzed by using linear models which tested for post-treatment effects on the criterion measures, while controlling for the effects of the pretreatment covariates (Jennings, 1971).

Since a repeated measures design was used in which the same Ss received both levels of treatment, it was necessary to include a binary predictor variable for each $\underline{S}$ in each regression equation to control for the effect of Ss (Ward, personal communication, 1977). Incidentally, this procedure also provided a statistical control for possible order effects (in that a predictor for order is redundant i.e., a linear combination of a subset of the Subject variables). A non-interaction model between $\underline{S}$ and other predictors was assumed in the analyses.

For clinical pain the starting full model including all variables necessary to test Hypotheses 4 and 2 is stated as follows:

Model $I_{\text {C } 30}:$ Post $=a_{1}$ BPRE $+a_{2}$ PRI (S) $+a_{3}$ SPSHS $+E$ where Post* = a vector of the post-treatment clinical 
Pain Estimates for Session B (RIA);

$B P R E=$ a vector of the pre-treatment clinical

Pain Estimates for Session B (RIA);

$\operatorname{PRI}(S)=$ a vector of the $\mathrm{PRI}(S)$ scores from the MCGill Pain Questionnaire;

SPSHS $=$ a vector of the total scores for hypnotic susceptibility from the SPSHS:II;

$E=$ a vector of error terms for Model ${ }^{1}{ }_{\mathrm{C} 30^{\prime}}$

$a_{j}=$ least squares regression coefficients $(j=1-3)$.

For experimental pain the starting full model including all variables necessary to test Hypotheses 4 and 2 is stated as follows:

Model $l_{\text {E30 }}:$ Tol $=a_{1}$ Athres $+a_{2}$ Atol $+a_{3}$ Thres $+a_{4}$ PRI (S) $+a_{5}$ SPSHS $+E$

where Tol* $^{*}$ a vector of time to maximum pain tolerance for each $\underline{S}$ for session $B$ (RIA);

Athres $=$ a vector of time to pain threshold for each S for Session A (baseline);

Atol = a vector of time to maximum pain tolerance for each $\underline{S}$ for Session A (baseline);

Thres $=$ a vector of time to pain threshold for each $\underline{S}$ for Session $B$ (RIA);

PRI (S) = a vector of the PRI(S) scores from the

*Note that "Post" and "Tol" are criterion variables. 
McGill Pain Questionnaire;

SPSHS $=$ a vector of the total scores for hypnotic susceptibility from the SPSHS:II;

$E=$ a vector of error terms for Model $1_{E 30}$;

$a_{j}=$ least squares regression coefficients

$(j=1$ to 5$)$.

For clinical pain the starting full model including all variables necessary to test Hypotheses 3 and 1 is stated as follows:

Model $1_{\mathrm{C} 60}:$ Post $=a_{1} \operatorname{Txl}+a_{2} \operatorname{Tx} 2+a_{3} B P R E+a_{4} \operatorname{CPRE}$ $+a_{5}$ PRI $(S)+a_{6}$ SPSHS $+s_{i} S^{(i)}+E$

where Post* = a vector of the post-treatment clinical Pain Estimates for both Sessions B (RIA) and C (placebo);

$\mathrm{TXI}=\mathrm{a}$ vector of treatment level for session $\mathrm{B}$ $(R I A)$;

$\mathrm{Tx} 2$ = a vector of treatment level for session $\mathrm{C}$ (placebo);

$B P R E=a$ vector of the pre-treatment clinical Pain Estimates for Session B (RIA);

CPRE = a vector of the pre-treatment clinical Pain Estimates for Session C (placebo); PRI $(S)=a$ vector of the PRI(S) scores from the MCGill Pain Questionnaire;

*Note that "Post" and "Tol" are criterion variables. 
SPSHS $=$ a vector of the total scores for hypnotic susceptibility from the SPSHS:II;

$S^{(i)}=$ binary vectors of $l$ for the ith $\underline{S}, 0$ otherwise ( $i=1$ to 30$)$;

$E=$ a vector of error terms for Model $1_{\mathrm{C} 60}$;

$a_{j}=$ least squares regression coefficients $(j=1$ to 6$)$;

$\mathbf{s}_{i}=$ least squares regression coefficients $(i=1$ to 30$)$;

For experimental pain the starting full model including all variables necessary to test Hypotheses 3 and 1 is stated as follows:

Model $I_{E 60}:$ Tol $=a_{1} T \times 1+a_{2} T_{x 2}+a_{3}$ Athres $+a_{4}$ Atol

$$
\begin{aligned}
& +a_{5} \text { Thres }+a_{6} \text { PRI }(S)+a_{7} \text { SPSHS } \\
& +s_{i} S(i)+E
\end{aligned}
$$

where Tol* = a vector of time to maximum pain tolerance for each $\underline{S}$ for both sessions $B$ (RIA) and

C (placebo);

$\mathrm{Txl}=\mathrm{a}$ vector of treatment level for session $\mathrm{B}$ (RIA);

$\mathrm{Tx} 2=\mathrm{a}$ vector of treatment level for session $\mathrm{C}$ (placebo);

Athres $=$ a vector of time to pain threshold for each $S$ for Session A (baseline);

*Note that "Post" and "ToI" are criterion variables. 
Atol $=$ a vector ot time to maximum pain tolerance for each $\underline{S}$ for Session A (baseline); Thres $=a$ vector of time to pain threshold for each $\underline{S}$ for both Sessions B (RIA) and C (placebo);

PRI $(S)=a$ vector of the PRI(S) scores from the McGill Pain Questionnaire;

SPSHS $=$ a vector of the total scores for hypnotic susceptibility from the SPSHS:II;

$S^{(i)}=$ binary vectors of $I$ for the ith $\underline{S}, 0$ otherwise ( $i=1$ to 30$)$;

$E=$ a vector of error terms for Model $I_{E .60}$; $a_{j}=$ least squares regression coefficients $(j=1$ to 7$)$;

$s_{i}=$ least squares regression coefficients $(i=1$ to 30$)$.

The hypotheses were tested by successive comparisons of the full model (having the greater number of predictors) with the restricted model (having the smaller number of predictors). The resulting F-ratios provided tests of the reduction of the squared multiple correlation coefficients $\left(\underline{R}^{2} s\right)$. Tables 1 and 2 summarize the results of testing Hypotheses 4 and 2 for clinical and experimental pain, respectively. Tables 3 and 4 summarize the results of testing Hypotheses 3 and 1 for clinical and experimental pain, respectively. The four tables show the variables excluded 
or combined, the number of predictors, the degrees of freedom, and the values of $\underline{\mathrm{R}}^{2}$ for each model; the models compared; and the value of $\underline{F}$ for each comparison. (Note that Tables 1 and 2 are based on only one treatment session i.e., RIA, while Tables 3 and 4 are based on both RIA and placebo sessions.)

Table 1

Comparison of Full and Restricted Models for Clinical Pain for Hypotheses 4 and 2

\begin{tabular}{|c|c|c|c|c|c|c|}
\hline Model & $\begin{array}{l}\text { Variables } \\
\text { Excluded }\end{array}$ & $\begin{array}{l}\text { Number of } \\
\text { Predictors } 1\end{array}$ & df & $\underline{\mathrm{R}}^{2}$ & $\begin{array}{c}\text { Models } \\
\text { Compared } \\
\text { Full- } \\
\text { Restricted }\end{array}$ & $\underline{F}$ \\
\hline $1_{\mathrm{C} 30}$ & None & 4 & & .8624 & & \\
\hline 2 & PRI (S) & 3 & $1 / 26$ & .8607 & $1_{\mathrm{C} 30^{-}}-2$ & 0.32 \\
\hline 3 & SPSHS & 2 & $1 / 27$ & .8570 & $2-3$ & 0.71 \\
\hline
\end{tabular}

Table 2

Comparison of Full and Restricted Models for Experimental Pain for Hypotheses 4 and 2

\begin{tabular}{|c|c|c|c|c|c|c|}
\hline Model & $\begin{array}{l}\text { Variables } \\
\text { Excluded }\end{array}$ & $\begin{array}{l}\text { Number of } \\
\text { Predictors } 1\end{array}$ & df & $\underline{R}^{2}$ & $\begin{array}{l}\text { Models } \\
\text { Compared } \\
\text { Full- } \\
\text { Restricted }\end{array}$ & $\underline{F}$ \\
\hline
\end{tabular}

\begin{tabular}{lllllll}
$I_{E 30}$ & None & 6 & \multicolumn{5}{c}{.7616} \\
2 & PRI (S) & 5 & $1 / 24$ & .7466 & $I_{E 30}-2$ & 4.16 \\
3 & SPSHS & 5 & $1 / 24$ & .7204 & $1_{E 30}-3$ & 1.58 \\
\hline
\end{tabular}

$I_{\text {An additional predictor (i.e., the unit vector) was }}$ included in the starting full model and successive models a result of using the Statistical Package for the Social Sciences (SPSS) to solve the regression equations. 
Table 3

Comparison of Full and Restricted Models for Clinical Pain for Hypotheses 3 and 1

\begin{tabular}{|c|c|c|c|c|c|c|}
\hline Model & $\begin{array}{l}\text { Variables Excluded } \\
\text { or Combined }\end{array}$ & $\begin{array}{l}\text { Number of } \\
\text { Predictors } 1\end{array}$ & $\underline{d f}$ & $\underline{\mathrm{R}}^{2}$ & $\begin{array}{l}\text { Models } \\
\text { Compared } \\
\text { Full- } \\
\text { Restricted }\end{array}$ & $\underline{F}$ \\
\hline$I_{\mathrm{C} 60}$ & None & 32 & & .9619 & & \\
\hline 2 & Exclude SPSHS & 31 & $1 / 28$ & .9524 & $I_{660^{-}}-2$ & $6.78 *$ \\
\hline 3 & Exclude PRI(S) & 31 & $1 / 28$ & .9575 & $I_{\mathrm{C} 60^{-}}-3$ & 3.14 \\
\hline 4 & Combine BPRE \& CPRE & 30 & $1 / 29$ & .9538 & -4 & 2.46 \\
\hline 5 & Combine $T \times 1 \& T \times 2$ & 29 & $1 / 30$ & .9486 & -5 & 3.46 \\
\hline
\end{tabular}
${ }^{{ }^{p} \underline{p}<.05}$.

Table 4

Comparison of Full and Restricted Models for Experimental Pain for Hypotheses 3 and 1

Model Variables $\begin{gathered}\text { Number of } \\
\text { Predictors }\end{gathered} \quad$ df $\quad \underline{R}^{2}$\begin{tabular}{c}
$\begin{array}{c}\text { Models } \\
\text { Compared } \\
\text { Full- } \\
\text { Restricted }\end{array}$ \\
\hline
\end{tabular}

$\begin{array}{lllllll}I_{\text {E60 }} & \text { None } & 32 & & .9845 \\ 2 & \text { SPSHS } & 31 & 1 / 28 & .9839 & I_{E 60}-2 & 1.20 \\ 3 & \text { PRI (S) } & 30 & 1 / 29 & .9839 & 2-3 & 0.00 \\ 4 & \text { TXI } & 29 & 1 / 30 & .9830 & 3-4 & 1.80\end{array}$

$l_{\text {Because linear dependencies are contained in the set }}$ of predictors for Model 1 , the actual full model in the statistical analysis contalns only 32 linearly independent predictors.

${ }^{2}$ Because linear dependencies are contained in the set of predictors in Model $l_{E 60}$, the actual full model in the statistical analysis contains only 32 linearly independent predictors. 
Tables 5 and 6 show the means, standard deviations, and intercorrelations of the variables defined in the starting full model and combinations of these variables used in later linear models (without square root transformations) .

Table 5

Means and Standard Deviations of Variables

\begin{tabular}{lrr} 
Variable & Mean & S.D. \\
\hline SPSHS & 8.83 & 7.83 \\
PRI (S) & 25.94 & 12.69 \\
Athres & 34.50 & 39.85 \\
Bthres 1 & 36.60 & 40.45 \\
Cthres 1 & 39.26 & 40.90 \\
Thres & 37.93 & 40.37 \\
Atol & 102.77 & 73.40 \\
Btol2 & 112.43 & 78.58 \\
Ctol & 114.37 & 82.47 \\
Tol & 113.40 & 79.87 \\
BPRE & 44.90 & 30.55 \\
CPRE & 43.70 & 29.83 \\
Pre & 44.30 & 28.72 \\
Bpost 3 & 35.53 & 28.97 \\
Cpost & 38.10 & 26.97 \\
Post & 36.82 & 27.39
\end{tabular}

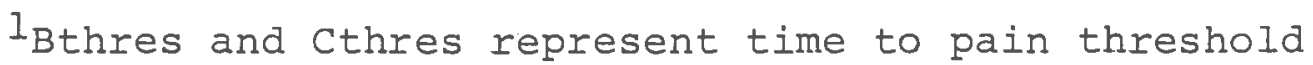
on the Tourniquet Test for Sessions B (RIA) and C (placebo), respectively.

2 Btol and Ctol represent time to maximum pain tolerance on the Tourniquet Test for sessions $B$ (RIA) and C (placebo), respectively.

3 Bpost and Cpost represent post-treatment Pain Estimates for Sessions $B$ (RIA) and C (placebo), respectively. 
Table 6

Intercorrelations of Variables

Variable

\begin{tabular}{|c|c|c|c|c|c|c|c|c|c|c|}
\hline Variable & SPSHS & PRI & Athres & Atol & Thres & Tol & BPRE & CPRE & PRE & POST \\
\hline SPSHS & & .17 & -.11 & .13 & -.11 & .18 & .07 & .12 & .21 & .05 \\
\hline PRI & & & -.05 & .12 & -.03 & -.08 & .26 & .30 & .58 & .47 \\
\hline Athres & & & & .42 & .95 & .40 & -.06 & -.08 & -.15 & -.20 \\
\hline Atol & & & & & .41 & .81 & .02 & -.02 & .00 & -.01 \\
\hline Thres & & & & & & .43 & -.09 & -.07 & -.17 & -.20 \\
\hline Tol & & & & & & & -.02 & -.09 & -.12 & -.13 \\
\hline BPRE & & & & & & & & -.55 & .49 & .42 \\
\hline CPRE & & & & & & & & & .46 & .44 \\
\hline Pre & & & & & & & & & & .90 \\
\hline
\end{tabular}

Post

The hypotheses were tested in the order $4,2,3$, and 1. Hypotheses 4 and 2 were tested first to determine whether chronic pain experience (as measured by the PRI(S) score from the McGill Pain Questionnaire) and hypnotic susceptibility (as measured by the total score from the SPSHS:II) should be included as covariates in the analyses to test Hypotheses 3 and 1. Hypothesis 3 which tests for interaction was then evaluated before Hypothesis 1 which tests for main effects.

Hypothesis 4 states that the effect of RIA on (a) clinical pain and (b) experimental pain is significantly 
related to chronic pain experience when the effect of hypnotic susceptibility is controlled. To evaluate this hypothesis a full model, which included the PRI(S) score from the McGill Pain Questionnaire was compared with a restricted model, which excluded the PRI(S) score, using an $F$ test. For clinical pain the $F$ ratio was not significant, $\underline{F}(1,26)=0.32, \underline{p}>.05$; for experimental pain the $\underline{F}$ ratio was not significant, $\underline{F}(1,24)=4.16, \underline{p}>.05$. The hypothesis is therefore rejected.

Hypothesis 2 states that the effect of RIA on (a) clinical pain and (b) experimental pain is not significantly related to hypnotic susceptibility when the effect of chronic pain experience is controlled. To evaluate this hypothesis a full model, which included the total score for hypnotic susceptibility from the SPSHS:II was compared with a restricted model, which excluded the score for hypnotic susceptibility, using an $\underline{F}$ test. For clinical pain, the $\underline{F}$ ratio was not significant, $\underline{F}(1,27)=0.71, \underline{p}>.05$, and for experimental pain the $\underline{F}$ ratio was not significant, $\underline{F}(1,24)=1.58, \underline{p}>.05$. The hypothesis is therefore supported.

Hypothesis 3 states that differences between the effect of RIA and the effect of an oral placebo on clinical pain are not constant for different levels of pretreatment clinical Pain Estimates when the effects of hypnotic susceptibility and chronic pain experience are 
controlled. To evaluate this hypothesis a full model which included separate predictors for session B (RIA) and Session C (placebo) pre-treatment clinical Pain Estimates, was compared with a restricted model which combined the pre-treatment clinical Pain Estimates into one predictor for the two sessions. This ocmparison provided a test for interaction (i.e., nonhomogeneous slopes). The $\underline{E}$ ratio was not significant, $\underline{E}(1,29)=2.46, \underline{p}>.05$, and the hypothesis of nonhomogeneous slopes is rejected.* Hypothesis 1 states that RIA is significantly more effective than an oral placebo in (a) reducing clinical pain, and (b) increasing experimental pain tolerance when the effects of hypnotic susceptibility and chronic pain experience are controlled. To evaluate this hypothesis a full model which included separate predictors for Session B (RIA) and Session C (placebo) treatment effects was compared with a restricted model which combined treatment effects for the two sessions into one predictor (i.e., the unit vector). For clinical pain the $F$ ratio was not significant, $F(1,30)=3.46$. p $>05$. Similarly, for experimental pain the $\underline{F}$ ratio was not significant, $\underline{F}(1,30)=1.80, \underline{p} .05$. The hypothesis is therefore rejected, i.e., there is no difference in treatment effects.

* Note that Hypothesis 3 applies only to clinical pain. 


\section{DISCUSSION}

Interpreting the results of the present study involves examining the interrelationships between individual characteristics of the $\underline{s}, i . e .$, his chronic pain experience, pre-treatment level of clinical pain, and hypnotic susceptibility; and the treatment effects.

The results of this study support one of the two hypotheses derived from Joseph Barber's results in applying RIA to dental pain (Hypotheses 1 and 2). In review, Joseph Barber found RIA to be effective in the control of subthreshold electrical tooth stimulation regardless of $\underline{s}^{\prime} s$ hypnotic susceptibility. He also found RIA to be effective in the control of acute clinical dental pain (although hypnotic susceptibility was not measured in these Ss).

In the present study RIA was not significantly more effective than an oral placebo in (a) reducing clinical pain and (b) increasing experimental pain tolerance (when hypnotic susceptibility was controlled). These results indicate that for clinical and experimental pain, the initial effectiveness of RIA or placebo is comparable. Although this result initially seems in conflict with $\mathrm{J}$. Barber's work, Barber in fact never compared the effect of RIA with a control group. He demonstrated the effect of RIA for experimental pain by measuring pain threshold 
electrical tooth stimulation before implementing RIA, after delivering the post-hypnotic cue for analgesia, and after returning $\underline{S}$ s to their normal level of awareness.

Additionally, in the present study, the effect of RIA on clinical and experimental pain was not significantly related to hypnotic susceptibility (when the effect of chronic pain experience is controlled). These results support J. Barber's premise that the effectiveness of RIA (an indirect hypnotic approach) is not related to hypnotic susceptibtility. Nevertheless, they do not corroborate his findings that for all Ss RIA successfully raised the pain threshold for electrical tooth stimulation to an arbitrarily defined limit regardless of hypnotic susceptibility.

Interestingly, when the effects of RIA and placebo are combined into a single treatment variable, the effect of treatment on clinical pain is related to hypnotic susceptibility. (See Table 3.) This implies that the effect of placebo treatment is significantly related to hypnotic susceptibility, a finding which represents another departure from the literature.

The results of the present study do not support Hypotheses 3 and 4 . Both of these hypotheses are concerned with the relationship between the effect of treatment and either chronic pain experience or pre-treatment level of clinical pain. The results of testing Hypothesis 4 
indicate that the effect of RIA on clinical pain and experimental pain is not significantly related to chronic pain experience (when the effect of hypnotic susceptibility is controlled). Therefore, the PRI(S), which measured chronic pain experience, did not contribute significantly to the variance and it was not included as a covariate in the subsequent analyses. It may be noted, however, that the PRI(S) and the pre-treatment clinical Pain Estimate are significantly correlated, $\underline{\underline{r}}(28)=.58, \underline{p}<.01$. The pre-treatment clinical Pain Estimate was included as a covariate in all subsequent analyses to determine the effect of treatment on clinical pain.

The results of testing Hypothesis 3 indicate that for clinical pain there is no interaction between the effect of RIA, the effect of an oral placebo, and different levels of pre-treatment clinical Pain Estimate (when the effect of hypnotic susceptibility is controlled). Thus, there are no significant relationships between the effect of treatment (RIA or placebo) and either chronic pain experience or pre-treatment level of clinical pain.

The use of SCI male veterans who suffer from chronic pain syndrome may have contributed to the lack of a significant difference in treatment effect for RIA VS. placebo in the present study (when the effect of hypnotic susceptibility was controlled). For example, one would expect to find the effects of treatment attenuated when dealing 
with individuals who may be financially compensated for their pain, who frequently have disrupted family lives, and who often function in a social milieu in which alcohol/ drug abuse is encouraged.

One of the primary contributions of the present study is support for the position that results obtained from studies using acute pain or experimental pain (in the absence of clinical pain) cannot be generalized to the control of chronic pain. It may be unrealistic to expect a single exposure of any technique to have significant impact on pain in an individual whose lifestyle has been altered to accommodate chronic pain. This population difference may explain the differences between our findings and those of J. Barber, who used acute or brief experimental dental pain in healthy $\underline{S}$.

A number of frequently-cited studies in the literature on the control of pain were done with samples of individuals who had acute pain or who were subjected to short-term experimental pain in the absence of clinical pain (Bonica, 1974; Melzack, 1973; Sternbach, 1974; Weisenberg, 1977). Discrepancies between the results of the present study and those studies reflect legitimate differences in the effective control of chronic benign pain vs. experimental pain, acute pain, and other pain syndromes. Beecher $(1959,1963,1972)$ has argued that it is not possible to equate laboratory pain with clinical pain 
produced by pathological processes because the former is not accompanied by the anxiety associated with the disease process and the threat of disfigurement or death. Similarly, those who treat patients who have chronic benign pain contend that it is not possible to equate acute clinical pain with chronic pain because acute pain is not accompanied by the emotional components of long-term depression and anxiety (Fordyce, 1976; Sternbach, 1974). It is essential that the nature of the pain under investigation be recognized before generalizing from the results of studies in the control of pain. The results presented here are applicable specifically to chronic benign pain of somatogenic origin.

With regard to generalizability, practioners/ researchers who are interested in applying the results of pain control studies to individual chronic pain patients must be aware of how the data were obtained, the type of pain stimuli used, the conditions of testing, the independent measures used, how the data were analyzed, and the validity of the conclusions drawn.

It has frequently been noted that placebo and hypnotic analgesia seem to involve the elements of suggestion, expectations of successful outcome, and anxiety relief (T. X. Barber, 1969; Chaves \& T. X. Barber, 1974). Chaves and T. X. Barber assert that many of the positive claims for hypnosis are based on a readiness by the individual to accept suggestions, rather than an actual hypnotic effect. 
They conclude that effective pain control depends on a positive doctor-patient relationship, rather than on hypnotic effectiveness. To speculate further, the chronic pain patient, compared to a nondisabled individual, has a vastly more complex and often negative learning history with regard to "people-helping" professionals, and therefore may be unable to respond to a brief supportive contact. The results of the present study are consistent with $T$. X. Barber's theoretical orientation if one accepts the premise that one or two exposures are not sufficient to develop a positive doctor-patient relationship when the patient suffers from a chronic pain syndrome.

The present study indicates that: (a) RIA is not as widely applicable as J. Barber implied; (b) the effectiveness of RIA is not related to the individual's hypnotic susceptibility; and (c) the effectiveness of RIA is not related to the severity of the individual's chronic pain experience.

It is this author's belief that the impact of any one-session treatment is of limited value when evaluating the potential for effectively managing an individual's chronic pain. There is a paucity of other research comparing the effectiveness of different pain management procedures using chronic benign pain patients. Adaitional studies which involve multiple exposures to treatment over time are needed. Such studies are necessary to verify predictors of effective long-term pain management, and to 
compare the efficacy over time of different management procedures.

Further research to investigate and clarify the applicability of RIA for pain reduction in other chronic pain samples is desirable, since the effectiveness of the RIA technique has to date only been studied using acute/ experimental dental pain and chronic benign pain (this study) .

It would be interesting to evaluate the effectiveness of RIA in reducing clinical pain using repeated exposures to that technique. A comparison of hypnotic analgesia produced in response to direct suggestions vs. indirect suggestions (as in RIA) would also be of value.

Furthermore, investigation of practitioner variables (including patient ratings of practitioners) which enhance or detract from the successful application of RIA (or other hypnotic approaches) deserves more study, especially in view of the position taken by Chaves and T. X. Barber. In the current study RIA was implemented by a licensed clinical psychologist who has used hypnosis extensively in the management of chronic pain for the last seven years. Nevertheless, Joseph Barber might have obtained different results as a function of differences in style. In short, the RIA technique, while new, clearly deserves further research, as do other indirect hypnotic approaches.

The statistical control of the effect of pretreatment clinical pain ratings utilized here is recom- 
mended in further research with pain patients since this covariate, as in this study, is likely to account for a sizeable proportion of the variance. The measurement of hypnotic susceptibility is a necessity in studies involving hypnosis and may be desirable in studies involving selfregulatory procedures, e.g., biofeedback, relaxation, etc.

The need for experimental pain measures in the study of chronic clinical pain is questionable. The use of experimental pain is essential only in those studies which do not use pain patients; generalizing the results of such studies to real pain patients is usually inappropriate. In research using pain patients, experimental pain measures do not contribute useful information. In the final analysis, chronic pain patients' beliefs about the effectiveness of treatment. and an increased ability to participate in more productive lifestyles are the sine qua non of effective pain management. 
CONCLUSION

The major purpose of the present study was to see if RIA is as widely applicable as J. Barber implied. In fact, it is not, but $J$. Barber was correct in asserting that the effectiveness of RIA is unrelated to hypnotic susceptibility. Furthermore, the severity of chronic pain experience that an individual brings to the treatment situation does not necessarily influence the effectiveness of RIA in controlling his pain.

At present, the use of hypnosis for the control of clinical pain is limited, because of the widely accepted view that hypnotic analgesia can be effective only in a minority of patients (J. Barber, 1976). Hypnosis is therefore used by many practitioners who work in the field of chronic pain only as a last resort. Our findings, however, suggest that hypnotic susceptibility may not be a predictor of effective pain control when an indirect approach (such as RIA) is used. The regular incorporation of indirect hypnotic approaches into chronic pain management programs is appropriate, and practitioners need not refrain from offering hypnosis as a means of pain control on the basis of low hypnotic susceptibility.

In retrospect, it may have been optimistic to expect substantial pain relief from a single RIA session in our 
chronic pain patients. Although the severity of chronic pain experience was not related to the effect of RIA in this study, the analysis was handicapped by the lack of significant pain relief resulting from the single RIA session. The severity of pain experience that the individual brings to the treatment situation remains a potentially important variable. Further investigation to clarify the role of existing pain on response to pain management procedures is needed.

As noted elsewhere, the RIA technique, while new and unexplored, seems to bear considerable promise for the relief of pain. A major contribution of this work appears to be that chronic and acute pain must be dealt with as different entities by pain researchers dealing with RIA. This specific result buttresses the general position held by those who work with chronic pain patients that the distinction between chronic and acute pain states is important (Fordyce, 1976; Sternbach, 1974). Further research is necessary to specify and clarify the parameters of successful clinical pain reduction through RIA, so that the technique can be further developed and optimally applied. 
REFERENCES

Barber, J. The efficacy of hypnotic analgesia for dental pain in individuals of both high and low hypnotic susceptibility. Unpublished doctoral dissertation, University of Southern California, 1976.

Barber, J. Rapid induction analgesia: A clinical report. American Journal of Clinical Hypnosis, 1977, 19, 133137 .

Barber, T.X. The effects of "hypnosis" on pain: A critical review of experimental and clinical findings. Psychosomatic Medicine, 1963, 25, 303-332.

Barber, T.X. Hypnosis: A scientific approach. New York: Van Nostrand Reinhold, 1969.

Beecher, H. K. Measurement of subjective responses: Quantitative effects of drugs. New York: Oxford University Press, 1959.

Beecher, H. K. Quantification of the subjective pain experience. Proceedings of the American Psychopathological Association, 1963, 53, 111-128.

Beecher, H. K. The placebo effect as a non-specific force surrounding disease and the treatment of disease. In R. Janzed, W. D. Keidel, A. Herz, C. Steichele, J. P. Payne, \& R. A. P. Burt (Eds.), Pain: Basic principles, pharmacology, therapy.

Bonica, J. J. (Ed.), Advances in neurology. Vol. 4 Pain. New York: Raven Press, 1974.

Bottenberg, R. \& Ward, J. H. Applied multiple linear regression analysis. Office of Technical Services, Department of Commerce, Washington, D. C., 1960.

Caldwell, I. S. \& Smith, R. P. Pain and endurance of isometric muscle contractions. Journal of Engineering Psychology, $1966,5,25-32$.

Carver, D. W. et al. Report MDC El 570. A survey and analysis of military computer-based training systems: Vol. II, A descriptive and predictive model for evaluating instructional systems. Report prepared for the Defense Advanced Research Projects Agency (ARPA), 1400 Wilson Blvd., Arlington, Virginia, 1977. 
Chaves, J. F. \& Barber, T. X. Hypnotism and surgical pain. In T. X. Barber, N. P. Spanos, \& J. F. Chaves (Eds.), Hypnosis, imagination, and human potentialities. New York: Pergamon Press, 1974.

Dorpat, T. L. \& Holmes, T. H. Mechanisms of skeletal muscle pain and fatigue. Archives of Neurology and Psychiatry, 1955, 74, 628-640.

Erickson, M. H. The confusion technique in hypnosis. American Journal of Clinical Hypnosis, 1964, 6, 183207.

Erickson, M. H., \& Erickson, F. Concerning the nature and character of posthypnotic behavior. Journal of General Psychology, 1941, 24, 95-133.

Erickson, M. H., Hershman, S., \& Sector, I. The practical application of medical and dental hypnosis. New York: Julian Press, 1961.

Erickson, M. H., Rossi, E. L., \& Rossi, S. I. Hypnotic realities. New York: Irvington Publishers, Inc., 1976.

Evans, F. J. Suggestibility in the normal waking state. Psychological Bulletin, 1967, 67, 114-129.

Evans, F. J. Placebo response: Relationship to suggestibility and hypnotizability. Proceedings of the 77th Annual Convention of the American Psychological Association, 1969, 889-890.

Evans, F. J. The placebo response in pain reduction. In J. J. Bonica (Ed.), Advances in neurology. Vol. 4. Pain. New York: Raven Press, 1974.

Evans, M. B. \& Paul, G. I. Effects of hypnotically suggested analgesia on physiological and subjective responses to cold stress. Journal of Consulting \& Clinical Psychology, 1970, 35, 362-371.

Fordyce, W. E. Behavioral methods for chronic pain and illness. Saint Louis: Mosby, 1976.

Gottfredson, D. K. Hypnosis as an anesthetic in dentistry. Unpublished doctoral dissertation, Brigham Young University, 1973.

Hilgard, E. R. A quantitative study of pain and its reduction through hypnotic suggestion. Proceedings of the National Academy of Sciences, 1967, 57, 1531-1586. 
Hilgard, E. R. \& Hilgard, J. R. Hypnosis in the relief of pain. Los Altos, Calif.: William Kaufman, Inc., 1975.

Jennings, E. Linear models underlying the analysis of covariance residual gain scores and raw gain scores. Unpublished manuscript, University of Texas, Austin, 1971.

Kerlinger, F. N. \& Pedhazur, E. J. Multiple regression in behavioral research. New York: Holt, Rinehart \& Winston, Inc., 1973.

Lauer, L. W. Factorial components of hypnotic susceptibility. Unpublished doctoral dissertation, Stanford University, 1965.

Lewis, T. Pain. New York: Macmillan, 1942.

Mayer, D., Price, D., Barber, J., \& Rafii, A. Acupuncture analgesia: Evidence for activation of a pain inhibitory mechanism of action. In Bonica, J. J. (Ed.), Proceedings of the First world Congress of the International Association for the Study of Pain. New York: Raven Press, 1976.

McGlashan, T. H., Evans, F. J., \& Orne, M. T. The nature of hypnotic analgesia and placebo response to experimental pain. Psychosomatic Medicine, 1969, 31, 227246 .

Melzack, R. The puzzle of pain. New York: Basic Books, 1973.

Melzack. R. The McGill Pain Questionnaire: major properties and scoring methods. Pain, 1975, 1, 277299.

Orne, M. T. Pain suppression by hypnosis and related phenomena. In J. J. Bonica (Ed.), Advances in neurology, Vol. 4. Pain, New York: Taven Press, 1974 .

Shor, R. E. Explorations in hypnosis: A theoretical and experimental study. Unpublished doctoral dissertation, Brandeis University, 1959.

Shor, R. E. Physiological effects of painful stimulation during hypnotic analgesia under conditions designed to minimize anxiety. International Journal of Clinical \& Experimental Hypnosis, 1962, 10, 183-202.

Sternbach, R. A. Pain: A psychophysiological analysis. New York: Academic Press, 1968. 
Sternbach, R. A. Pain patients: traits and treatment. New York: Academic Press, 1974.

Sternbach, R. A., Murphy, R. W., Akeson, W. H., \& Wolf, S. R. Chronic low-back pain: the "low-back loser." Postgraduate Medicine, 1973, 53, 135-138.

Sternbach, R. A., Murphy, R. W., Timmermans, G., Greenhoot, J.H., \& Akeson, W. H. Measuring the severity of clinical pain. In J. J. Bonica (Ed.L, Advances in neurology. Vol. 4. Pain, New York: Raven Press, 1974 .

Ward, J. H. \& Jennings, E. Introduction to linear models. Englewood Cliffs, N.J.: Prentice-Hall, Inc., 1973.

Walker, H. \&. Lev, J. Elementairy statistical methods. (rev. ed.), New York: Holt, Rinehart \& Winston, Inc., 1958 .

Weisenberg, M. Pain and pain control. Psychological Bulletin, 1977, 84, 1008-1044.

Weitzenhoffer, A. M., \& Hilgard, E. R. Stanford Hypnotic Susceptibility Scale, Forms A and B. Palo Alto, Calif.: Consulting Psychologists Press, 1959.

Weitzenhoffer, A. M., \& Hilgard, E. R. Stanford Hypnotic Susceptibility Scale, Form C. Palo Alto, Calif.: Consulting Psychologists Press, 1962.

Weitzenhoffer, A. M., \& Hilgard, E. R. Stanford Profile Scales of Hypnotic Susceptibility, Forms I and II. Palo Alto, Calif.: Consulting Psychologists Press, 1967.

Wolff, H. G. \& Wolf, S. Pain (2nd ed.), Springfield, Ill.: Thomas, 1958.

Woodforde, J. M., \& Merskey, H. Personality traits of patients with chronic pain. Journal of Psychosomatic Research, 1972, 16, 167-172. 
APPENDIX

Rapid Induction Analgesia Procedure

The purpose of the following procedure is to develop complete analgesia and muscular relaxation in as short a time as possible (approximately 10 minutes).

I'd like to talk with you for a moment to see if you'd like to feel more comfortable and relaxed than you might expect. Would you like to feel more comfortable than you do right now?

I'm quite sure that it will seem to you that I have really done nothing, that nothing has happened at all. You may feel a bit more relaxed, in a moment, but I doubt that you'll notice any other changes. I'd like you to notice, though, if you're surprised by anything else you might notice. OK, then.. the really best way to begin feeling more comfortable is to just begin by sitting as comfortably as you can right now . . go ahead and adjust yourself to the most comfortable position you like . . . that's fine. Now, I'd like you to notice how much more comfortable you can feel by just taking one very big, satisfying deep breath. Go ahead. . big, deep, satisfying breath. - That's fine. You may already notice how good that feels . . how warm your neck and shoulders 
can feel.. Now, then.. I'd like you to take four more very deep, very comfortable breaths... and, as you exhale, notice. . just notice how comfortable your shoulders can become. . and notice how comfortable your eyes can feel when they close. . . and when they close, just let them stay closed. . that's right, just notice that. . and notice, too, how, when you exhale, you can just feel that relaxation beginning to sink in . . Good, that's fine.. - now, as you continue breathing, comfortably and deeply and rhythmically, all I'd like you to do is to picture in your mind . . . just imagine a staircase, any kind you like. . . with 20 steps, and you at the top. . Now, you don't need to see all 20 steps at once, you can see any or all of the staircase, any way you like.. . that's fine.. . Just notice yourself, at the top of the staircase, and the step you're on, and any others you like. . however you see it is fine... Now, in a moment, but not yet, I'm going to begin to count, out loud, from one to 20, and. . as you may already have guessed . . as I count each number I'd like you to take a step down that staircase . . see yourself stepping down, feel yourself stepping down, one step for each number I count . . and all you need to do is notice, just notice, how much more comfortable and relaxed you can feel at each step, as you go down the staircase.. one step for each number that I count. . the larger the number, the farther down the staircase.. . the farther 
down the staircase, the more comfortable you can feel. . one step for each number. . all right, you can begin to get ready. . now, I'm going to begin.. . one.. one step down the staircase.. . two.. . two steps down the staircase.. that's fine.. THREE.. three steps down the staircase. . and maybe you already notice how much more relaxed you can feel . . I wonder if there are places in your body that feel more relaxed than others. . - perhaps your shoulders feel more relaxed than your neck - . perhaps your legs feel more relaxed than your arms - . I don't know, and it really doesn't matter . . all that matters is that you feel comfortable.. . that's all - . FOUR . . four steps down the staircase, perhaps feeling already places in your body beginning to relax . . - I wonder if the deep relaxing, restful heaviness in your forehead is already beginning to spread and flow . . down, across your eyes, down across your face, into your mouth and jaw . . down through your neck, deep, restful, heavy . . FIVE . . five steps down the staircase. . a quarter of the way down, and already beginning perhaps, to really enjoy your relaxation and comfort . . SIX . . . six steps down the staircase. . perhaps beginning to notice that the sounds which were distracting become less so. - that all the sounds you can hear become a part of your experience of comfort and relaxation... anything you can notice becomes a part of your experience of comfort and relaxation... SEVEN . . seven steps down the 
staircase. . that's fine.. perhaps noticing the heavy, restful, comfortably relaxing feeling spreading down into your shoulders, into your arms . . I wonder if you notice one arm feeling heavier than the other . . perhaps your left arm feels a bit heavier than your right. . . perhaps your right arm feels heavier than your left. . . I don't know, perhaps they both feel equally, comfortably heavy . . It really doesn't matter . . just letting yourself become more and more aware of that comfortable heaviness . . . or is it a feeling of lightness? I really don't know, and it really doesn't matter . . EIGHT . . eight steps down the staircase . - perhaps noticing that, even as you relax, your heart seems to beat much faster and harder than you might expect, perhaps noticing the tingling in your fingers . . perhaps wondering about the fluttering of your heavy eyelids. . . NINE. . . nine steps down the staircase, breathing comfortably, slowly, and deeply - . restful, noticing that heaviness really beginning to sink in, as you continue to notice the pleasant, restful, comfortable relaxation just spread through your body . . . TEN . . ten steps down the staircase. . halfway to the botton of the staircase, wondering perhaps what might be happening, perhaps wondering if anything at all is happening . . and yet, knowing that it really doesn't matter, feeling so pleasantly restful, just continuing to notice the growing, spreading, comfortable relaxation. . - ELEVEN . . eleven steps down the staircase... 
noticing maybe that as you feel increasingly heavy, more and more comfortable, there's nothing to bother you, nothing to disturb you, as you become deeper and deeper relaxed . . TWELVE . . twelve steps down the staircase - . I wonder if you notice how easily you can hear the sound of my voice. . how easily you can understand the words I say . . with nothing to bother, nothing to disturb . . THIRTEEN . . thirteen steps down the staircase, feeling more and more the real enjoyment of this relaxation and comfort . . FOURTEEN . . fourteen steps down the staircase. . noticing perhaps the sinking, restful pleasantness as your body seems to just sink down, deeper and deeper into the chair, with nothing to bother, nothing to disturb . . as though the chair holds you, comfortably and warmly . . FIFTEEN . . Eifteen steps down the staircase . . three-quarters of the way down the staircase . . deeper and deeper relaxed, absolutely nothing at all to do . . but just enjoy yourself . . SIXTEEN . . sixteen steps down the staircase . . wondering perhaps. what to experience at the bottom of the staircase . . and yet knowing how much more ready you already feel to become deeper and deeper relaxed . . more and more comfortable, with nothing to bother, nothing to disturb . . SEVENTEEN . . seventeen steps down the staircase. - closer and closer to the bottom, perhaps feeling your heart beating harder and harder, perhaps feeling the heaviness in your arms and legs become even 
more clearly comfortable . . knowing that nothing really matters except your enjoyment of your experience of comfortable relaxation, with nothing to bother, nothing to disturb . . EIGHTEEN . . eighteen steps down the staircase. - almost to the bottom, with nothing to bother, nothing to disturb, as you continue to go deeper and deeper relaxed . . heavy . . comfortable . . restful . . relaxed . . nothing really to do, no one to please, no one to satisfy . . just to notice how very comfortable and heavy you can feel, and continue to feel as you continue to breathe, slowly, and comfortably . . restfully - . NINEteEn . . nineteen steps down the staircase - . almost to the bottom of the staircase . . nothing to bother, nothing to disturb you as you continue to feel more and more comfortable, more and more relaxed, more and more rested . . more and more comfortable. . just noticing . . and now . . TWENTY . . bottom of the staircase. . . deeply, deeply relaxed . . deeper with every breath you take. . . as I talk to you for a moment about something you already know a lot about . . remembering and forgetting. . . you know a lot about it, because we all do a lot of it . . every moment, of every day you remember . . and then you forget, so you can remember something else... you can't remember everything, all at once, so you let some memories move quietly back in your mind. . . I wonder, for instance, if you remember what you had for lunch yesterday. . I would guess that, 
with not too much effort, you can remember what you had for lunch yesterday . . and yet.. . I wonder if you remember what you had for lunch a month ago today... I would guess the effort is really too great to dig up that memory, though of course it is there. . . somewhere, deep in the back of your mind. . . no need to remember, so you don't - . and I wonder if you'll be pleased to notice that the things we talk about today, with your eyes closed, are things which you'll remember tomorrow, or the next day - . or next week. . I wonder if you'll decide to let the memory of these things rest quietly in the back of your mind. . or if you'll remember gradually, a bit at a time - . or perhaps all at once, to be again resting in the back of your mind . . perhaps you'll be surprised to notice that this room is the place for memory to surface - . perhaps not. . perhaps you'll notice that it is more comfortable to remember on another day altogether - . it really doesn't matter. . doesn't matter at all - . whatever you do, however you choose to remember. . - is just fine. . absolutely natural . . doesn't matter at all. . whether you remember tomorrow or the next day, whether you remember all at once, or gradually . . . completely or only partially . . whether you let the memory rest quietly and comfortably in the back of your mind . . really doesn't matter at all . . and, too, I wonder if you'll notice that you'll feel surprised that your visit here today is so much more pleasant and com- 
fortable than you might have expected. . . I wonder if you'll notice that surprise . . that there are no other feelings . . perhaps you'll feel curious about that surprise. . . surprise, curiosity. . I wonder if you'll be pleased to notice that today . . . and any day . . whenever you notice that you are sitting in this room like this.. . when you feel your back resting against your chair like this . . you'll feel reminded of how very comfortable you are feeling right now . . even more comfortable than you feel even now . . comfortable, relaxed - . nothing to bother, nothing to disturb... I wonder if you'll be reminded of this comfort, too, and deep relaxation, by just noticing the column of mercury in front of you . . perhaps this comfort and relaxation will come flooding back, quickly and automatically, whenever you find yourself sitting in front of this table.. I Ion't know exactly how it will seem. . . I only know, as perhaps you also know . . that your experience will seem surprisingly more pleasant, surprisingly more comfortable, surprisingly more restful than you might expect. . . with nothing to bother, nothing to disturb . . whatever you are able to notice. . everything can be a part of your experience of comfortableness, restfulness and restfulness and relaxation. . everything you notice can be a part of being absolutely comfortable. . . and I want to remind you that whenever Dr. Snow touches your right shoulder, like this.. . whenever it is appropriate, and only when 
it is appropriate. . . whenever Dr. Snow touches your right shoulder, like this... or whenever I touch your right shoulder, like this . . you'll experience a feeling . . a feeling of being ready to do something . . whenever I touch your right shoulder, like this.. . or whenever Dr. Snow touches your right shoulder, like this - . you'll experience a feeling . . a feeling of being ready to do something . . perhaps a feeling of being ready to be relaxed . . perhaps a feeling of being ready to be even more comfortable.. . perhaps ready to know even more clearly that there's nothing to bother, nothing to disturb. . perhaps ready to become heavy and tired . . I don't know . . but whenever Dr. Snow touches your right shoulder, like this . . you'll experience a feeling . . a feeling of being ready to do something . . it really doesn't matter . . perhaps just a feeling of being ready to be even more surprised . . it doesn't really matter . . nothing really matters but your experience of comfort and relaxation . . . absolutely deep comfort and relaxation.. . with nothing to bother and nothing to disturb. . that's fine.. . and now, as you continue to enjoy your comfortable relaxation, I'd like you to notice how very nice it feels to be this way .. . to really enjoy your own experience, to really enjoy the feelings your body can give you . . . and in a moment, but not yet.. not until you're ready . . but in a moment I'm going to count from one to 20 . . and as you know, 
I'd like you to feel yourself going back up the steps . . one step for each number. . You'll have all the time you need . . after all, time is relative... feel yourself slowly and comfortably going back up the steps, one step for each number I count. . . more alert as you go back up the steps, one step for each number I count. . . when I reach three, your eyes will be almost ready to open . . when I reach two, they will have opened . . and, when I reach one, you'll be alert, awake, refreshed. . . perhaps as though you'd had a nice nap . . alert, refreshed, comfortable. . and even though you'll still be very comfortable and relaxed, you'll be alert and feeling very well. . perhaps surprised, but feeling very well - . perhaps ready to be surprised . . no hurry, you'll have all the time you need, as you begin to go back up these restful steps . . TWENTY . . NINETEEN . . . EIGHTEEN . . that's right, feel yourself going back up the steps . . . ready to be surprised, knowing what you had for lunch yesterday, and yet . . SEVENTEEN . . SIXTEEN . . FIFTEEN . . a quarter of the way back up, more and more alert. . . no rush, plenty of time... feel yourself becoming more and more alert . . FOURTEEN . . THIRTEEN . . . TWELVE . . ELEVEN . . TEN . . halfway back up the stairs. . more and more alert. . comfortable but more and more alert . . NINE. . that's right, feel yourself becoming more and more alert. . . EIGHT . . SEVEN . . SIX . . FIVE . . FOUR . . . 
THREE . - that's right . . TWO . . and ONE . . that's right, wide awake, alert, relaxed, refreshed... that's fine. How do you feel? Relaxed? Comfortable? Since the subject has been given posthypnotic suggestions as part of the initial hypnotic experience, it is now possible to elicit an even more satisfactory hypnotic state (including development of analgesia) by utilizing one or more of the posthypnotic cues suggested. Whenever in the future cues are properly given, the subject rapidIy and automatically develops a satisfactory hypnotic state and is adequately analgesic for clinical procedures. 